\title{
УДК 347.91/.95
}

\section{ПРОБЛЕМЫ ЗАЩИТЫ ИНТЕЛЛЕКТУАЛЬНЫХ ПРАВ}

\author{
Губайдуллина Эльмира Хамитовна \\ к.ю.н., доцент кафедры гражданского и арбитражного процесса
}

Рябова Инна Сергеевна

СГЭУ

Аннотация: актуальность темы определяется, прежде всего, тем, что интеллектуальный продукт является одной из важнейших составляющих экономического, научного, производственного потенциала страны. Цель представленной работы - исследование проблем защиты интеллектуальных прав. Методология исследования - анализ научной литературы по заданной проблеме, а также практического отечественного опыта.

Ключевые слова: интеллектуальные права, проблема, защита, интеллектуальная собственность, гражданский оборот.

\section{PROBLEMS OF INTELLECTUAL PROPERTY RIGHTS PROTECTION}

\section{Gubaidullina Elmira Khamitovna Ryabova Inna Sergeevna}

\begin{abstract}
: the relevance of the topic is determined primarily by the fact that an intellectual product is one of the most important components of the country's economic, scientific, and production potential. The purpose of this paper is to study the problems of intellectual property rights protection. Research methodologyanalysis of scientific literature on a given problem, as well as practical domestic experience.
\end{abstract}

Key words: intellectual rights, problem, protection, intellectual property, civil turnover.

В течение последних лет происходят заметные изменения, связанные с защитой интеллектуальных прав. Усиливается активность участников рынка гражданского оборота, общественное правосознание ведет к увеличению количества платного использования контента в интернете. В течение последних 
лет было реформировано законодательство, которое касается защиты интеллектуальных прав. А еще появилась многообразная судебная практика [1, c. 29-32].

Поэтому можно с уверенностью сказать о происходящих положительных изменениях в системе защиты прав интеллектуальной собственности. Тем не менее, остаются проблемы правового характера. Несмотря на повышение качества оформления прав на результаты интеллектуальной деятельности, они все еще продолжают оставаться под угрозой на фоне неконтролируемого копирования и распространения произведений через интернет.

Действующие средства индивидуализации результатов интеллектуальной деятельности не могут обеспечить их полноценную защиту. Чаще всего проблемы защиты интеллектуальных прав выявляются в результате решения споров в этой области [2, с. 255-261].

Остановимся на конкретных проблемах. К примеру, в современной практике полностью отсутствуют конкретные критерии расчета и процесса взыскания компенсации за нарушение исключительных прав. В соответствии с законодательством Российской Федерации, если произошло нарушение исключительного права, то правообладатель обращается к требованию компенсации, а не взысканию убытков. Размер компенсации определяется индивидуально, однако сумма варьируется примерно от 10 тысяч рублей до 5 миллионов рублей, также может быть применен двойной размер стоимости объекта исключительного права.

Осуществление выбора формы взыскания компенсационных выплат всегда определяется самостоятельно со стороны правообладателя. Однако здесь существует существенная проблема - формирование требований о назначении компенсации в стоимостном варианте. Ведь в рамках законодательства не установлены четкие критерии расчета данной компенсации, отражены только минимальная и максимальная сумма для взыскания [3, с. 114-122].

Именно поэтому правообладатели в произвольном порядке назначают размер компенсации, что практически всегда означает об отсутствии объективной оценки данного размера выплаты. Однако могут произойти и иные ситуации, когда по решению суда размер взыскиваемой компенсации уменьшатся по решению суда.

До 2017 г. суды имели теоретическую возможность для снижения размера компенсации ниже минимального порога, который составляет 10 тыс. руб. В 2016 г. КС РФ выпустил Постановление №28-П. В нем указывается на 
возможность снижения суммы компенсации только при условии, что исключительные права в отношении одного правообладателя индивидуальным предпринимателем нарушаются многократно и касаются только одного объекта интеллектуальной собственности. Вместе с тем суд по-прежнему обязан принимать во внимание материальное положение ответчика, решая вопрос о размере компенсации. Судом должно быть установлено, осуществляет ли ответчик предпринимательскую деятельность, совершается ли правонарушение впервые, проявляются ли со стороны ответчика другие действия при совершении нарушения. Размер компенсации должен отвечать требованиям о разумности, а оценка действий нарушителя должна быть сформирована судом. Даже эти разъяснения не вносят ясности в ситуацию со снижением компенсационной выплаты ниже минимальной суммы [4, с. 109-114].

Также следует указать внимание и на тот факт, что одной из насущных проблем является практически полное отсутствие защиты правового поля режиссеров-постановщиков, на что неоднократно обращали свое внимание специалисты этой области. На уровне закона механизмов защиты их прав в отношении объектов интеллектуальной собственности не предусматривается. Поэтому защита авторских прав театральных режиссеров-постановщиков попрежнему не работает, хотя она и предусматривается в отношении авторских прав режиссеров аудиовизуальных произведений. По данным на 2019 г., изменения в законодательстве о защите интеллектуальных прав в отношении театральных режиссеров все еще находятся на рассмотрении ГД РФ.

По-прежнему существует неопределенная ситуация с защитой права на неприкосновенность произведений. К примеру, практическая деятельность указывает на частоту возникновения ситуаций, где необходимо проводить четкое разграничение права на переработку произведения и права на неприкосновенность. Ведь не стоит забывать о том, что право на переработку это исключительные права, а неприкосновенность - это личные неимущественные права, принадлежащих автору. Критериев для разграничения этих прав в законе и по результатам судебной практики не установлено [5].

Поэтому получается, что в каждом конкретном случае суду приходится самому решать, является ли переработка новым произведением или созданное произведение является лишь основой чего-то ранее созданного.

Есть и такие ситуации, когда в результате переработки отдельных произведений даже с учетом внесенных в них изменений новые произведения так и не появляются. И решить данный спорный вопрос можно только в 
результате назначения и проведения экспертизы. Первоначальное же суждение о разграничении права на переработку и права на неприкосновенность является чисто субъективным. По закону предусмотрена возможность истребования компенсации морального вреда с нарушителя права на неприкосновенность. Более того, автор имеет возможность требовать запрета на использование произведения в искаженном виде.

Что касается возможности удовлетворения требований о запрете использования произведения, то она не ставится в зависимость от того, а были ли в результате нарушений какие-либо негативные последствия, к примеру, для деловой репутации автора, в ряде стран такое требование по закону предусмотрено. Существование этой проблемы на практике приводит к тому, что требование о запрете использования произведения может быть несоразмерным совершенному правонарушению в отношении результатов интеллектуальной деятельности.

Есть проблема с параллельным импортом оригинальных товаров. Легализация параллельного импорта товаров до настоящего времени не осуществлена. Требованиями о маркировке товара предусматривается обязательность наличия согласия от правообладателя при ввозе товаров на территорию России. При отсутствии такого согласия товар признается контрафактом, не имеет значение оригинальная природа происхождения продукции, а также возможность осуществления маркировки товара товарным знаком правообладателем.

Помимо всего прочего, в Российской Федерации предусматривается серьезная ответственность за ввоз подделок в страну.

Данная проблема - это давнее противоречие, поэтому до сих пор актуализируется вопрос необходимости ограничения применения к нарушителям ответственности без вины. В данном случае речь идет об установлении ограничения на уничтожение и изъятие.

Также особенно хотелось бы отметить и то, что злоупотребление интеллектуальными правами способно реализовываться и в виде троллинга. Данная понятие представляет собой процесс регистрации товарных знаков с целью минимизации конкуренции на рынки и для искусственного увеличения срока, либо расширения сферы патентов. Троллинг - это достаточно популяризированный инструмент продления срока охраны авторского права. Причем, многие правонарушители делают это в виде искусственного включения соавтором задним числом после смерти автора. 
В настоящее время абсолютно отсутствует единообразная правоприменительная практика в системе оспаривания охраны объектов интеллектуальной собственности.

Предлагаем более подробно рассмотреть подходы разрешения споров в судебном порядке в анализируемой отрасли права.

Одного подхода к разрешению споров придерживается Суд по интеллектуальным правам, иного подхода придерживается Палата по патентным спорам, предъявляя свои требования к стандартам доказывания и процессуального регулирования. Есть проблема и с неопределенностью отдельных сроков регистрации, отведенных на регистрацию объектов и права перехода, сроков по рассмотрению запросов и споров.

Экспертное сообщество все больше склоняется к точке зрения о том, что действующая система управления авторскими правами является несовершенной. Каких-либо реально действующих механизмов для коллективной защиты авторских прав правообладателей в настоящее время не сделано, однако продолжают существовать аккредитованные организации в части коллективной защиты прав и интересов правообладателей. За годы существования таких организаций их эффективность деятельности не подтверждена. И одной из причин является отсутствие прозрачной отчетности перед самими правообладателями. Те же продюсерские музыкальные центры произвольным образом устанавливают размеры вознаграждений и сборов. И вся прибыль от сотрудничества артистов с такими музыкальными центрами по большей части оседает в карманах их руководителей.

Денежные средства непосредственно до правообладателей (авторов музыкальных произведений - текстов и музыки) не доходят. Функции и правомочность таких организаций тоже четко не установлены.

Соответственно, часто возникают споры между руководителями таких организаций и авторами произведений. Реальной конкуренции между деятельности таких центров в России пока не сложилось. С учетом совокупности всех выявленных проблем по результатам проведения исследования необходимо указать на необходимость применения комплексного подхода для реформирования существующей системы, связанной с защитой интеллектуальных прав. Есть недовольство со стороны владельцев торговых марок, авторов произведений и тех аккредитованных организаций, которые должны использовать инструменты коллективной защиты прав интеллектуальной собственности. Сложившийся порядок в области прав 
интеллектуальной собственности неэффективен в плане их защиты. Проблемы можно было бы решить с внесением изменений в законодательство.

При этом к разработке изменений в соответствующие законы должны быть подключены сами правообладатели и другие заинтересованные стороны. При подготовке изменений необходимо обратить внимание на сложившуюся судебную практику, сделать более жесткой ответственность за нарушение интеллектуальных прав только при условии, что эти нарушения повлекли за собой негативные последствия.

\section{Список литературы}

1. Савченко Е.Я. Проблемы определения способов защиты гражданских прав в современном гражданском обществе // Правопорядок: история, теория и практика. 2015. № 2 (5). С. 29-32.

2. Полозова Д.В. Самозащита интеллектуальных прав в договорных отношениях // Юридическая наука и практика: Вестник Нижегородской академии МВД России. 2014. № 2 (26). С. 255-261.

3. Файзрахманов К.Р. Признание права или обременения отсутствующим в системе способов защиты вещных прав // Актуальные проблемы российского права. 2016. № 4 (65). С. 114-122.

4. Филиппова Т.А. Проблемы применения норм Гражданского кодекса РФ о защите интеллектуальной собственности // Вестник Омского университета. Серия «Право». 2015. № 2 (31). С. 109-114.

5. Павлова Е.А., Калятин В.О., Корнеев В.А. Вводный научный комментарий к части четвертой ГК РФ [Электронный ресурс]. 2019. Доступ из справ.-правовой системы «КонсультантПлюс».

(C) Э.Х. Губайдуллина, И.С. Рябова, 2020 